\title{
Drivers of Digital Transformation in Manufacturing
}

\author{
Kirsten Liere-Netheler \\ University of Osnabrück \\ kirsten.liere-netheler@uos.de
}

\author{
Sven Packmohr \\ Malmö University \\ sven.packmohr@mah.se
}

\author{
Kristin Vogelsang \\ University of Osnabrück \\ kristin.vogelsang@uos.de
}

\begin{abstract}
Digital transformation is one of the most current topics for the manufacturing industry. This transformation affects the operational value creation process, enables new ways of doing business and leads to fundamental changes in organizations. However, the implementation of new digital technologies, as well as the realization of these changes, still face many difficulties. It is important to understand organizational and individual adoption processes. Which drivers push the adoption of digital technologies in manufacturing? We used a qualitative research approach to gain in-depth insights from interviews with 16 participants. For digital transformation in manufacturing, we identified 12 drivers as well as perceived or expected advantages that arise with the technology use. Companies are mainly motivated by the goal of process improvement and demands communicated by their customers. We aim to strengthen the understanding of the whole disruptive and vast changing processes which are ongoing in manufacturing.
\end{abstract}

\section{Introduction}

Digital transformation seizes the modern world and is expected to change the whole process of value creation in industries [1]. This phenomenon can be observed in many countries all over the world under different names. In North America, the term "industrial internet" describes a similar transformation like "Industrie 4.0" [2] in Germany and "industrial value chain initiative" [3] in Japan as well as "smart industry" [4]. Up to now, digital transformation is a very prominent discussion topic for researchers and professionals, but the understanding of sociotechnical processes that correspond with their uses is still underdeveloped [5], [6]. A great amount of research is so far published mainly in the field of engineering. This leads to a push for technologies whereas results regarding the sociotechnical perspectives are rare. Research from an industrial sociologic perspective shows that the development, diffusion and implementation of new technologies in digital transformation still face many difficulties [6]. A clear understanding of the factors that lead to the implementation of digital technologies in manufacturing is necessary; but still missing. Executives might want to measure the success of digital initiatives. Without the awareness of what drives success factors forward, it will be hardly possible to influence success. Therefore, it is of great importance to understand the nature of drivers for digital transformation to shape a mature discussion about hopes and fears [1], [6] associated with the disruptive change. Furthermore, the digital transformation does not only affect individuals but also the organizational level. Especially, crossorganizational relations will be forced to become redesigned [2], [3]. Besides the diverse possibilities of digital transformation exigencies also evolve. Government and legislation have to develop an adequate framework for these innovative areas. These external requirements will concern leaders and followers of the digital transformation equally. To make digital transformation a success, it is important to know and understand which needs and desires of individuals and organizations have to follow this revolution of production processes [7]. There are multiple reasons that drive the use of digital production technologies forward. To understand the mechanism of implementation processes enables the enterprises to prepare the application duly in order to make it a successful configuration [5].

The research gap enables to contribute to the following research question: „Which drivers foster the adoption of digital technologies?"

The first very innovative enterprises already emphasized the effects of the digital transformation. To learn from these innovators is a great chance. To understand the adoption processes and expectations linked with the phenomenon of digital transformation is of value for enterprises. For this reason, we sense the topic as being of interest and of valuable contribution.

Owing to the weak empirical basis in this field, we used a qualitative research approach which can be classified as an explorative research method [8], [9]. We based our study on Grounded Theory approach by Glaser and Strauss [10]. To gain an in-depth insight on drivers of digital transformation, we collected data from 16 semi-structured interviews with experts from different industrial enterprises from Germany. Because of the different backgrounds, we could gain widespread knowledge from different perspectives. For this reason, we take a holistic view [11], related to digital transformation. We expect this approach to be more of general value than a narrow view on single technologies. 
In the following, we will give a short overview of research on digital transformation. Moreover, we describe the term "drivers" and classify it to the main research streams. Afterwards, we present the main drivers deduced from the qualitative data and analyze their role in the process of pushing digital transformation forward.

\section{Literature review and theoretical base}

What will be changed by the digital transformation and which areas of business are affected? A lot of research has already been done to describe the technical implications of digital transformation. However, there is little research available that deals with the sociotechnical understanding of reasons why institutions decide to digitalize their way of value creation. In the following sections, we will illustrate what research regarding drivers and technology adoption means and why it is so special in the context of digital transformation. Furthermore, we will give a detailed view on prevailing research streams dealing with digital innovations, in order to show the current research gap.

\subsection{Understanding the drivers of innovation}

The innovative character of digital transformation is a challenge for enterprises and people [7]. "The rather disruptive process concerning the transformation of companies into their digitalized counterparts constitutes an element of uncertainty and difficulty for many decision makers." [12] According to Rogers [13] an innovation can be regarded as an idea, practice, or object that is considered as new. Schumpeter defines five areas in which innovations happen: product, method of production, customers, suppliers and organization [14]. Following this idea, the organizational change that comes along with the digital transformation can be regarded as a kind of an innovation. According to the dominant technologies, the changing impact on manufacturing processes is vast.

In the field of innovation research, the understanding of the process of technology adoption plays an important role. Adoption is "a decision to make full use of an innovation as the best course of action available" [13]. Several research streams deal with the adoption processes that occur when new technologies (and innovations) enter the market. The adoption proceeds on different levels, as it impacts and is influenced by the behavior of individuals, organizations and their environment. In the following, we will give a short overview of the major research streams of innovation adoption and their corresponding results:

The research stream that deals with the major influence factors which foster the technology use of human beings is the technology acceptance research. It is based on the Technology-Acceptance Model (TAM) by Davis [15]. The TAM is strongly influenced by the theory of planned behavior [16] and the theory of rea- soned action [17]. The goal of this research stream is to predict human behavior (concerning technology use). A corresponding research stream is the so-called appropriation research. It gives a broader impression on the interplay between human and technology during the whole lifecycle [18]. A similar framework of the use during the lifecycle is given by representatives of the IT adoption research based on the results of Rogers [13], although these models aim at the market view. Additional to the impact factors that control the individual use, environmental influence factors must also be considered. The environmental influence on technology adoption is presented within the so called Technology-Organization-Environment Framework (TOE) [19]. It displays the relationship between the environment, the technology and the organization. This leads to another stream of adoption research: organizational adoption which means the organizational needs of adoption in relation to immanent economical results. Well-known representatives follow the idea of the transaction cost theory [20] and the famous IS success model [21]. This model implies antecedents of IS success from different dimensions. Aspects from the individual level of IS use are combined with economic advantages and characteristics of the technology. The relation between the technological characteristics and the entrepreneurial task is also proven [22].

The differentiation of the adoption levels (individual, organization and external) is to some extend generic but also often used in adoption research [14]. Though we tried to align the theories presented to different sections, most of them include more levels. Especially the research stream that aims at the IS success, works with factors from all perspectives identified and is complex.

All findings from these different research streams have in common that they link the adoption process of technologies to the actual use (even TAM, although it is based on the theory of planned behavior and therefore on post-adoption believes). However, pre- and post-adoption processes differ [24]. The identification of drivers is primarily aligned to the pre-adoption processes because they are important before the use-phase. So far, they can be regarded as not experienced outcomes but perceived or expected advantages that arise with the technology use. This understanding of drivers differs from the characteristics of success factors. Success factors are defined as "those few things that must go well to ensure success $[\ldots]$ and [...] they represent those managerial or enterprise areas that must be given special and continual attention [...]" [25]. Though, drivers are free of measures. Because of the ubiquitous use of the term "driver", there is no general definition of the term. In the following, we will define drivers as preliminaries and/or expectations about future benefits that positively trigger and influence the (pre)adoption processes. Digital transformation - from a holistic view - yields nested and enduring adoption processes. 
However, the effect which arises from digital transformation differs from other IS innovations [7]. Digital transformation affects not only the way how things will be produced. It will also influence workplaces and the human machine-interaction [6]. It is expected to have disruptive social and economic consequences [26] and is hence different from other technological innovations [5]. The digital transformation still occurs and grows. Many enterprises are still at the beginning of a disruptive manufacturing change. To take a look at what has driven innovative firms into digital transformation can be a valuable and instructive insight for those who will follow. For this reason, we will focus on the preadoption drivers that impact application of digital technologies in manufacturing.

\subsection{Digital transformation in manufacturing}

Digital transformation is defined as "the use of new digital technologies (social media, mobile, analytics or embedded devices) to enable major business improvements (such as enhancing customer experience, streamlining operations or creating new business models)" [27]. Even though the technologies are not necessarily new [28]. The innovation is about "combinations of information, computing, communication, and connectivity technologies" [29]. This means the process of digital transformation is accompanied by information system use. And further: the strategy and not only the technology is in focus [30].

Digital transformation in manufacturing affects individuals (in their role as user and customers), as well as business units, enterprises and corporate networks [2]. The digital way of value generation is marked by an in-depth integration of customers and suppliers [5]. Digital transformation goes beyond the technical process and plays an important role even for sociotechnical structures [12]. This makes the digital transformation process different from the adoption of other new technologies.

In order to identify actual research in the field of our topic, we conducted a literature research. We explored the main areas discussed by researchers dealing with the change that is happening in manufacturing companies due to the digital transformation. This is the key to a) a general understanding of the fields of interest that rise with the digital transformation and b) understand what kind of research already exists in the field of drivers and adoption processes that impact digital transformation.

For our literature review, we used different databases to search through the AIS Senior Scholars' 'basket' of eight journals (see Table 1) [31]. They are identified as the main leading journals in IS research. Even though this limits the results and top lists like the 'basket of eight' have been criticized [32], we gain a representative overview of research from the community.

For a broad overview, we chose rather general search terms which include but are not limited to "digi- tal transformation", "digitalization", "digitization" or "industrial internet". We limited the hits to the last ten years because it was our aim to identify current topics. Reducing the search to title, abstract and key words, we received 191 hits. We did not include 23 hits which represented editorials, calls, comments, covers or forewords. The remaining articles were analyzed by reading the abstracts. We searched for articles matching the points of interest of our research. These criteria were: business perspective, the manufacturing industry or unknown field of application, implications or success of digital transformation.

Limiting the perspective helped to stay focused on business topics. Articles using an economical view were excluded. Moreover, we brought the manufacturing industry in focus. Some articles were not investigating a manufacturing firm but gaining results which are useful for manufacturers as well. We also took a closer look at papers dealing with impact- or successfactor research as well as driver- and innovation- or adoption-research to make sure the digital transformation process is in focus of the articles. This excludes for example research about knowledge management or offshoring. In the end, we could identify 67 research articles on digital transformation. Table 1 gives an overview of the number of articles in the IS Journals.

\section{Table 1. Articles on digital transformation}

\begin{tabular}{|c|c|}
\hline Journal & No. \\
\hline MIS Quarterly (MISQ) & 17 \\
\hline Journal of Information Technology (JIT) & 13 \\
\hline Information Systems Journal (ISJ) & 10 \\
\hline $\begin{array}{l}\text { European Journal of Information Systems } \\
\text { (EJIS) }\end{array}$ & 8 \\
\hline $\begin{array}{l}\text { Journal of Strategic Information Systems } \\
\text { (JSIS) }\end{array}$ & 7 \\
\hline Information Systems Research (ISR) & 6 \\
\hline $\begin{array}{l}\text { Journal of Management Information Systems } \\
\text { (JMIS) }\end{array}$ & 3 \\
\hline $\begin{array}{l}\text { Journal of the Association for Information } \\
\text { Systems (JAIS) }\end{array}$ & 3 \\
\hline Total & 67 \\
\hline
\end{tabular}

The remaining 67 articles were clustered in research streams. Doing so, we found four main research streams for digital transformation in manufacturing: business models (BM), digital strategy, innovation as well as IT infrastructure (II) and architecture (IA).

Most articles were found on the topic business models. The research stream is dominated by case studies. A specific technology investigated in this field is digital platforms (e.g. [33], [34]) which develops new ideas for communication and business opportunities.

Another identified research stream is digital strategy [35]. Technologies, like big data, [36] change the requirements for firms.

The research stream innovation is the one which is quite close to the field of interest for this paper. The 
stream highlights new opportunities and challenges caused by digital transformation. This leads to the need for new theorizing [37]. Innovation network becomes more important for enterprises because of digitalization [38]. E-leadership [39] and the role of incumbent firms [40] as well as the future of low-paid workers[6], [41] are discussed.

Finally, we identified information infrastructure and information architecture as one research stream in digital transformation (e.g. [42]).

Our literature review shows the wide focus of digital transformation research in manufacturing. Many articles could not be allocated which shows how diverse research on digital transformation is. Most articles are dependent on special technologies from the field of digitalization. The analysis of current research also proves a deficiency of articles with sociotechnical implications.

We identified 10 articles within the findings mentioned above, dealing with the research topic of drivers and adoption in digital transformation. The major subresearch areas were: the effects of adoption [43]-[46] and research on adoption processes [47], [48] or a combination of the topics [49]. But this research does not directly focus on the reasons that trigger digital transformation in enterprises. It is more linked to post adoption processes.

The findings of the literature research show: digital transformation is a major topic in IS research. The research focus is more on strategy and technology than on sociotechnical implications. If sociotechnical research occurs, it is concentrated on post adoption processes and effects.

\section{Research procedure}

Exploring the landscape of research in the field of information systems, one must confess: quantitative methods in IS research are still dominant [50], [51]. Due to the fact that "fast changing phenomena are difficult to investigate solely through the use of traditionally privileged methods" [50], we follow the calls for more qualitative research [52]-[54]. While ITadoption processes are frequently discussed from different levels using different underlying theories, the research area of drivers of digital transformation can be regarded as new and complex. A qualitative research process is appropriate in order to examine complex interactions between organizations, technologies and people [51], [55], [56].

The underlying qualitative research is mainly influenced by Grounded Theory [10]. It is designed, giving a cluster of guidelines and techniques for the research in social reality [57]. The core of Grounded Theory is to enable the development of theoretical suggestions from the text material [10]. Results can be compared to existing theories after finishing the coding process. We combined the techniques from Grounded Theory with the techniques that were provided by Mayring [8], which has also been proven as a useful method in order to receive well based explanations of a complex phenomenon [9].

As expected in Grounded Theory [58], it was our inherent purpose to act as neutral observers eager to receive answers from different perspectives and as forthright as possible. We conducted interviews which consisted of three main parts: (1) introduction of the interviewee (in order to create a trustful atmosphere), (2) interviewees definition: major characteristics of digital transformation (in order to develop a common understanding), (3) narrative description of the adoption process cases (who decides, when and on what information the decisions are based).

The interviews were conducted in German and afterwards translated by the authors for research purposes. All interviews were recorded and transcribed. We used the CAQDAS (Computer-Assisted Qualitative Data Analysis Software) QDA Miner. An "open coding" process according to the Grounded Theory approach [10] was conducted in order to develop iteratively a well prepared database. This means we sequentially adjusted the research for a simultaneous collection of data and analysis. This cross-fertilized relationship between analysis and data generation leads to a complex process of iterative revision [57]. The research process was characterized by a comparative method [10] in order to deduce logical and consistent drivers of digital transformation. All authors were permanently involved within the research process of data generation and analysis. This led to an repetitive deduction and discussion of categories and concepts [58]. The underlying data were revised several times in order to identify patterns and similarities as well as deviations. Doing so, we were able to detect 12 drivers that foster the use of digital technologies. These drivers might be interconnected and influence each other. They are independent, measurable and addressable by interventions. After identifying the categories, we used the qualitative content analysis according to Mayring [8] by selectively coding the material to identify the number of statements per category.

\section{Results}

The data collection took place between December 2016 and February 2017. We conducted 16 semistructured interviews. According to the guidelines of Grounded Theory, we combined the concept of theoretical sampling with a purposeful sampling approach [59]. We selected the sample for our research from a group of experts with different backgrounds and deviating usage experiences (see Table 2). All companies are active in the realm of manufacturing. E.g., the interviewed trading company has strong ties to their manufacturing suppliers. The interviews had an average duration of 40 Minutes. 15 out of 16 companies are classified as large companies with more than $250 \mathrm{em}$ ployees. 
Table 2. Interviewees with case numbers

\begin{tabular}{llll||c}
\hline Industry & \multicolumn{1}{c}{$\mathbf{D}$} & $\mathbf{U}$ & $\mathbf{C}$ & $\mathbf{A}$ \\
\hline Automotive & $1,8,14,15$ & 16 & & $\mathbf{5}$ \\
\hline Engineering & $2,5,6,7,9$ & & & $\mathbf{5}$ \\
\hline $\begin{array}{l}\text { Agriculture } \\
\text { machinery }\end{array}$ & & 4 & 13 & $\mathbf{2}$ \\
\hline Chemical & & 11,12 & & $\mathbf{2}$ \\
\hline $\begin{array}{l}\text { Heavy Industry } \\
\text { Trading }\end{array}$ & 10 & & & $\mathbf{1}$ \\
\hline $\begin{array}{l}\text { Supply-Chain } \\
\text { Consulting }\end{array}$ & & & 3 & $\mathbf{1}$ \\
\hline $\begin{array}{l}\text { (A)ll } \\
\text { (1) }\end{array}$ & $\mathbf{1 0}$ & $\mathbf{4}$ & $\mathbf{2}$ & $\mathbf{1 6}$
\end{tabular}

The interviewees work mainly in production departments or related divisions such as research and development, IT or general management. We could distinguish three different groups of respondents: the group of deciders (D), the user group (U) and consultants (C) from the field of digital transformation. From the two consultants, one is working in-house and one is working external. The cells under D, $\mathrm{U}$ and $\mathrm{C}$ assign the cases to the groups. E.g., case 16 is an interviewee from the automotive industry having a role as a user. The deciders are rated higher as they are the ones to come in contact with possible innovations first and decide about the usage. They are supported by consultants.

We identified 677 relevant statements concerning drivers of digital transformation. We only counted positive connotations of the drivers. Negative values were bundled as barriers and used to enrich further discussion in chapter 5 . The drivers were allocated to the adoption levels (see 2.1): external, organizational and individual. We define drivers as pre-conditions $(\mathbf{P})$ and opportunities as expected outcome (E). This addition helps to answer cause and effect questions.

Table 3. Drivers and their values

\begin{tabular}{|c|c|c|c|c|}
\hline $\begin{array}{l}\text { Le- } \\
\text { vel }\end{array}$ & Driver & Count & Cases & $\begin{array}{l}\text { Na- } \\
\text { ture }\end{array}$ \\
\hline \multirow{6}{*}{ 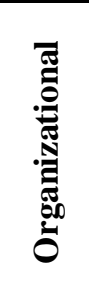 } & Process Improvement & 91 & 16 & $\bar{E}$ \\
\hline & $\begin{array}{l}\text { Workplace Improve- } \\
\text { ment }\end{array}$ & 80 & 15 & $\mathrm{E}$ \\
\hline & Vertical Integration & 70 & 15 & $\mathrm{P} / \mathrm{E}$ \\
\hline & Management Support & 51 & 14 & $\mathrm{P}$ \\
\hline & Horizontal Integration & 48 & 14 & $\mathrm{P} / \mathrm{E}$ \\
\hline & Cost Reduction & 32 & 10 & $\mathrm{P} / \mathrm{E}$ \\
\hline \multirow{5}{*}{ 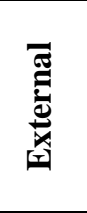 } & Customer Demands & 84 & 14 & $\mathrm{P} / \mathrm{E}$ \\
\hline & Supply Chain & 74 & 14 & $\mathrm{P} / \mathrm{E}$ \\
\hline & Innovation Push & 28 & 12 & $\mathrm{P}$ \\
\hline & Market Pressure & 25 & 10 & $\mathrm{P}$ \\
\hline & Laws/Government & 21 & 8 & $\mathrm{P}$ \\
\hline$\dot{-}$ & Employee Support & 73 & 14 & $\mathrm{P}$ \\
\hline Total & & 677 & 16 & \\
\hline
\end{tabular}

Calculating a revised calibration following Keller [60] would not change the rankings presented in Table 3 in general, which indicates that single interviewees did not influence the constituent results. Only minor deviations from the normal ranking could be identified. E.g., the drivers Customer Demands and Workplace Improvement changed places in the overall ranking.

The driver Process Improvement was named by all interviewees (see Table 3). The driver Laws/Government was least mentioned (in 8 cases), which still represents $50 \%$ of all interviews. The most used code is Process Improvement with 91 coded passages in the interview data. The least used code is Laws/Government with 21 statements. Six codes have frequencies above $10 \%$ and six have frequencies below $10 \%$.

In the following, we give a short description of the drivers and present some examples from the cases.

Process Improvement: Self-adapting systems take over the planning, control and execution of production. Perceived advantages are the increment of efficiency as well as reduction of error rates. Key innovations are: detective and predictive maintenance, process interlock and self-adjustment. "Process optimization is an important topic. [...] There is predictive maintenance, a keyword" [Case 5], "How can you interlock the process in order to prevent people from assembling things twice? That is the difference to usual production" [Case 9]

Workplace Improvement: The aim is to improve safety, ergonomics or usefulness. Complex or dangerous activities are performed by robots. In addition, the use of technologies can be adopted to ensure ergonomic work. "We do have high demands [concerning ergonomics] because we work with people here!" [Case 8]

Vertical Integration: Data is collected directly on operational level by sensor technology and is processed for integration on management level. Corresponding control information is sent back through the hierarchy to the production systems. With this exchange of information, the planning on production level can be more accurate with the opportunity to produce a higher variation of products and to produce in smaller batches. "We do this to produce more complex and more different versions." [Case 6]

Management Support: Management support includes the formulation of visions and strategies. It is an important feature of Management Support to provide the setting up structures, assigning responsibilities and hiring workforce. "The management pushed on the project. That was really important." [Case 12], "[Digitalization] is an important topic for us. Not only because the shareholder wants this. " [Case 1]

Horizontal Integration: "[...] refers to the integration of the various IT systems used in the different stages of the manufacturing and business planning processes that involve an exchange of materials, energy and information both within a company (e.g. in- 
bound logistics, production, outbound logistics, marketing) and between several different companies (value networks)." [2] The sales division is benefiting from the possibility to integrate with the customers purchasing department more accurately through new interfaces. Digitalization is expected to open up new business models. "We are eager to build and widen our business model. But there is a long way to go!" [Case 7], "That is our main focus. We want the digital transformation of the company. [...] We will open a platform even for other players in the market." [Case 10]

Cost Reduction: Digital transformation improves production processes and helps to reduce setup-times and breakdowns. This leads to comparative Cost Reductions. "When I want to benefit from quality and time-saving improvements I have to work in a networked way." [Case 16], "Decisions are always driven by costs!" [Case 1]

Customer Demands: The traceability of commodities and (intermediate) products through the whole production process is immanent for the quality assurance demanded by the customer. "The customer wants transparent traceability." [Case 9]

Supply Chain: The common planning and execution of operations with other companies, suppliers and customers impact the need for digital technologies. This leads to mutual design or R\&D activities as well as the exchange via trade fairs or conferences. "We expect the customer-supplier-chain to be improved." [Case 3], "It is my personal impression, and of this I am certain, the supplier profits from our long-term partnership and the common development of robots." [Case 8]

Innovation Push: New and innovative technologies lead to a push. New innovations are preliminary conditions that enable digitalization. Enterprises have to decide about the value of innovation. This increases the market competition. "This is the question: Will we be able to emphasize new potentials we won't have without the digital technology?" [Case 3]

Market Pressure: Companies experience lower margins and higher competition. Competitors already or soon will use advanced technologies. It is necessary to embrace these technologies to not fall behind the market standards and to secure competitive advantage in a globalized market. "We always take a look at our competitors." [Case 14], "Well it is not harassment, but there are many players acting in this market that want the market-share we want." [Case 14], "We have to be the first (introducing new technologies) to gain an advantage." [Case 15]

Laws/Government: The imposition of legal frameworks drives the use of technologies. These regulations affect environmental or sustainability standards. "I guess the government pushed the process to give the impression of taking action." [Case 3], "We emphasize clear judicial guidelines for new materials and new production systems. " [Case 8]
Employee Support: Digital systems help employees in performing their work. Work is perceived as simpler, more interesting and safer. In return, digitization is being driven forward with the support of the employees, their knowledge and inclination to use innovations. „From my perspective: it is fun. And the work saves my job." [Case 9], "[...] and it really makes my work easier!" [Case 11]

\section{Discussion}

The codes presented in Table 3 are based on interpretations of results and pre-knowledge of the coders. The names of the codes were deduced from the qualitative data and adjusted to terms of corresponding concepts known in the field of business studies such as vertical integration. We were able to detect three different groups of drivers. The classification is due to the effected levels and corresponds to former classifications [14]. The drivers could be allocated to organizational, external and individual drivers. Analysing the data, we identified a timeline for the emergence of these levels. External drivers are the first that come up. "It was all initiated by the German government a few years ago." [Case 4] External drivers are rather accepted [19]. They are often taken as given demands to be complied with. Innovation Push and Market Pressure force enterprises to act. Customer Demands for quality, flexibility and traceability stress the pressure. "This is driven by the desires of the customers because they have to pay for it." [Case 13] Expected quality improvements become an important matter. "It should be useful for the customer. We need to trace the quality of the charges." [Case 9] The mutual development of innovation -by integrating suppliers and customers- within the Supply Chain fertilises the innovative process. "We work a lot with the suppliers [...] the big innovations weren't something we made on our own." [Case 13]

One group of external drivers has a special role regarding the timeline. Laws often occur as a reaction of innovation. However, not all enterprises act on the same technological level. This is why laws and legal requirements also trigger adoption. Governments play an important role to design good conditions. Laws are perceived to lead to a higher quality of products and production processes. "We have to meet stricter threshold values. This leads to an enormous pressure to become better!" [Case 13] Furthermore, governmental parameters are frequently regarded as useful, especially aspects of data security and the distribution of standards. Standards and security issues are considered as one of the most important prerequisite to make digitalization a success [2]. However, a lot of fears also exist regarding security. "And if I cannot find a concept to constitute a safe IT and a safe data concept, it will be very difficult." [Case 7]

The second group of drivers are allocated to the organization. Organizational drivers push the develop- 
ment and cause new innovations. Table 3 proves that the interviewees perceive these to be most important. We assume these drivers might be of more interest to the interviewees, as they could be influenced actively. Almost all drivers express the anticipation of competitive advantages. This could indicate the need for companies to see Process Improvement as one of the main drivers as this is expected to lead to quality and output improvement as well as time-savings and a higher adaptability of production. "This is one pillar (of ...): the flexible factory. We are interested in all technologies that improve our transformation abilities." [Case 14] However, process improvement postulates knowledge of existing processes.

By providing data to internal and external users, coordination of processes can be accelerated. "Where entire logistics processes can then be completely automated and simplified." [Case 12] The Process Improvement runs throughout the enterprise and enables Vertical Integration of the divisions by internally linking different parts of the company together and making data available. "Our whole facility is connected to our database." [Case 12] This leads to a reduction of coordination costs [20]. Further Cost Reduction is expected to arise from the reduction of the error rate setup times and breakdowns. The interviewees referred to the decrease of manual labour: "Processes, which are to ensure extremely high quality, high reproducibility and simultaneously high output. In addition, quality assurance at high quantities [...] and this in Germany. This is only possible by automation." [Case 1] Meaning direct production costs could be reduced but also indirect costs, such as workforce, could be lowered with concurrent high quality. The need to comply with Customer Demands on the one hand and the need for Cost Reduction on the other has always been a dilemma in management [61]. Now the interviewees expect to be able to reach this goal. „Then I can offer high quality at comparatively lower prices in Germany." [Case 1] Nevertheless, digital transformation is combined with high capital expenditures: "Often, projects are not proceeding because of the high costs." [ Case 3]

The Vertical Integration enables the firm to develop new business strategies: "We hope for new business models by becoming more flexible and we hope to be able to produce even a lot size 1." [Case 7] This is possible by spreading the product variety as well as the service quality. The expansion of services, the Horizontal Integration, is a broadening of core competencies. There is a shift expected from mainly manufacturing to service-oriented-manufacturing, a paradigm shift of the value creation processes [62]. "It is step three to make a new vision, to see what I can do from the cloud. This would be at first: new business models." [Case 15] "That is the best: we will enable our customers to develop new business areas." [Case 2] And the interviewees even expect to tie customers more closely to the enterprise. "That is the progress, to tie the customer (to our business) and to receive much more information." [Case 3] Nevertheless, the interviewees fear a loss of individuality. "Yes, that is threatening, the loss of autonomy and encapsulation." [Case 3]

People involved in the change process are also identified as important drivers. Management Support is well-known in IS research [21]. Without the support of higher decision levels, there will be no allocation of resources. "In sum, you need support of the management." [Case 6] But the interviewees also perceive barriers regarding the change. "We have a resistance to change. Definitely. Starting from the management down to the blue collar!" [Case 10]

Besides management support, the involvement of employees in organizations plays an important role. Employee Support is the only identified driver on the individual level which is often subordinated during the pre-adoption phase. We assume that the individual level is becoming more important in the post-adoption phase when the individual acceptance of new technologies is in focus. In regards to the timeline it is a downstream driver. Employee support is immanent for the later success of adoption. Employees are not only operational workforce but need to get involved in changing processes. This support is characterized by individual perceptions, experiences and attitudes towards digital technology. The statements from our data lead to the suggestion that the driver can be split up into different constructs according to those from technology acceptance research [15]. Taking a closer look at the statements from the interviews, we detect a positive attitude towards new digital technology as the major impact factor. Users and deciders expect fun and positive emotions while developing digital solutions for manufacturing. This is probably motivated by the positive private experience with digital technologies. "And we do have people, who are leaning towards technique. And they ask: why don't we have this?" [Case 4] The participants also suppose an increased ease of use that comes from the use of smart technologies. To support the acceptance of the systems will be an urgent task for all enterprises. People also emphasize fears and threats related to digital transformation [6]. "It is a question of acceptance. [...] If it is a topic like digitalization, people become scared!" [Case 4]

In sum, many organizational drivers can directly be linked to later realized success factors. The drivers Horizontal Integration and Process Improvement contain basic constructs for IT success [21]. The drivers identified represent concepts companies have to think about before adopting a certain technology. Moreover, companies need to find employees as well as managers who are supporting the topic.

Besides the level classification in Table 3 , we added a second classification to be able to argue what the nature of the driver is. Drivers are preliminaries, like as conditions, that force the transformation process but they can also be positive expectations that trigger the change. This is in accordance with the TOE framework 
which includes environmental context as a component with constraints and opportunities [23]. Some drivers are immanent (such as innovation push) whereas other drivers raise expectations (cost reduction). With some drivers, the classification is overlapping as its nature can be of pre-condition and outcome at the same time. E.g., customer demands have a constraints and opportunity nature. On the one hand, the customers can set their demands. On the other hand, companies can better handle customer demands if they are prepared.

The drivers of digital transformation are different from those of other technologies. Especially the interplay of the drivers, the high complexity of production, services and external drivers clearly present the challenges of digital transformation. They indicate the enormous need for security measures and the introduction of standards to lower the risk for future investments in the area [63]. Enterprises need the capability to keep up with the development regardless of their position within the supply chain. Management has to emphasize the importance to develop innovation and accept the mutual interchange of technologies, data and ideas with the whole supply chain. Enterprises feel an increasing pressure coming from markets, competitors and new technologies. Even though people are afraid of the implications for the low paid jobs, the digital transformation is mainly carried out by a generation of people who like new technologies and expect the work in a digitalized enterprise to be fun.

In general, the interviewees answered rather homogeneous as indicated by the column Cases in Table 3 . An analysis of the codes less mentioned (Cost Reduction, Innovation Push, Laws and Market Pressure) indicates the following: The probability that Cost Reduction is mentioned by a decision maker is $70 \%$ whereas it is $50 \%$ for a consultant as well as a user. Innovation Push is mentioned by all consultants, but only $50 \%$ of the users. $80 \%$ of the decision makers mentioned Innovation Push. Both consultants talked about Laws and even $50 \%$ of the users. $40 \%$ of the decision makers used this code during their interviews. Moreover, Market Pressure was mentioned by all consultants and half of the users. $60 \%$ of the decision makers found it of importance.

\section{Conclusion and Outlook}

It is the goal of this paper to present an understandable and applicable framework of drivers of digital transformation in manufacturing. The conducted literature research shows a research gap in sociotechnical perception research, focusing on the detection and interpretation of adoption influences. The identification and analysis of drivers that foster the digital transformation in manufacturing is important for the understanding of pre-adoption processes from a research as well as from a practical viewpoint. The identification of drivers on different levels gives initial hints for correlated research such as acceptance and success.
The research presented helps to understand the whole disruptive and vast changing processes that are ongoing in manufacturing. We identified 12 drivers of digital transformation. We adopted a position from a holistic point of view. Knowing the drivers give enterprises, individuals and even standard-forming institutions the opportunity to shape the process of digital adoption positively and pro-actively.

This research can also be disposed to the important research stream of qualitative data generation that aims at a deeper understanding of processes that mold the MIS context. We based the research on a standardized concept, Grounded Theory [58], and qualitative data analysis [8] in order to gain the relevant data. The research process was done stepwise, documented and therefore traceable. According to general quality criteria for qualitative research [8], [60] the approach can be regarded as valid. As identical responses in interviews are not sufficient to claim general reliability, we hence assume reliable findings due to the number of cases and the proven homogeneity of responses.

Though, we carefully proceeded with the research, the presented examination is not free of limitations and further potentials might still arise. We strongly request continuous research such as quantitative methods and case studies in order to gain deeper insights on the effects and impacts of the drivers we detected. Besides, this study focusses on the group of decision makers. Deviations in comparison to users and consultants were minor. Combining our work with a mixed method research approach will give valuable insights not only to the description of the drivers but also on their impact and interplay regarding adoption processes. Meanwhile, the classification of drivers into pre-condition and expected outcome deserves more attention as this will help to practically guide decision makers. Additionally, this research can be used as a start for crossand multicultural studies. The underlying data was mainly derived from Germany. Therefore, external drivers are limited to Germany and Europe, due to EUwide legislation. Although we interviewed employees of multinational companies the drivers might differ in different countries. A comparison and cross-culture analysis may lead to further insights into this topic. Further research regarding aspects from different industries could use our research as an initial position in order to compare strategies of digital transformation.

\section{References}

[1] G. P. Pisano and W. C. Shih, "Does America really need manufacturing", Harv. Bus. Rev., vol. 90, no. 3, pp. 94-102, 2012.

[2] H. Kagermann, W. Wahlster, and J. Helbig, Recommendations for implementing the strategic initiative Industrie 4.0, acatech - National Academy of Science and Engineering, 2013.

[3] N. Uchihira, H. Ishimatsu, and K. Inoue, "IoT service business ecosystem design in a global, competitive, 
and collaborative environment", in Portland International Conference on Management of Engineering and Technology (PICMET), 2016, pp. 1195-1201.

[4] B. R. Haverkort and A. Zimmermann, "Smart Industry: How ICT Will Change the Game!", IEEE Internet Comput., vol. 21, no. 1, Jan. 2017, pp. 8-10.

[5] K. Schwab, The fourth industrial revolution, Penguin, London, 2017.

[6] E. Brynjolfsson and A. McAfee, The Second Machine Age: Work, Progress, and Prosperity in a Time of Brilliant Technologies, W. W. Norton \& Company, New York, NY, 2014.

[7] K. Zhu, S. Dong, S. X. Xu, and K. L. Kraemer, "Innovation diffusion in global contexts: determinants of post-adoption digital transformation of European companies”, Eur. J. Inf. Syst., vol. 15, no. 6, 2006, pp. 601-616.

[8] P. Mayring, Qualitative content analysis: theoretical foundation, basic procedures and software solution, SSOAR, Klagenfurt, 2014.

[9] K. Vogelsang, M. Steinhüser, and U. Hoppe, "A Qualitative Approach to Examine Technology Acceptance", in International Conference on Information Systems, Milan, ICIS 2013 Proceedings.

[10] B. G. Glaser and A. L. Strauss, The discovery of grounded theory : strategies for qualitative research, Aldine Publ. Co., Chicago, Ill., 1975.

[11] S. Devaraj and R. Kohli, "Performance Impacts of Information Technology: Is Actual Usage the Missing Link?", Manag. Sci., vol. 49, no. 3, pp. 60-95.

[12] C. Klötzer and A. Pflaum, "Toward the Development of a Maturity Model for Digitalization within the Manufacturing Industry's Supply Chain”, in Proceedings of the 50th Hawaii International Conference on System Sciences, 2017, pp. 4210-4219.

[13] E. M. Rogers, Diffusion of innovations, 5th ed., Free Press, New York, NY, 2003.

[14] J. A. Schumpeter, "Entrepreneurship as innovation", Entrepreneurship: The Soc. Sci. View, 2000, pp. 5175.

[15] F. D. Davis, "A technology acceptance model for empirically testing new end-user information systems: Theory and results", Massachusetts Institute of Technology, 1986

[16] I. Ajzen, "From intentions to actions: A theory of planned behavior", in Action Control - From Cognition to Behavior, J. Kuhl and J. Beckmann, Eds., Springer, Heidelberg, 1985, pp. 11-39.

[17] M. Fishbein and I. Ajzen, "Attitudes and voting behavior: An application of the theory of reasoned action", in: Progress in Applied Social Psychology, G. M. Stephenson and J. M. Davis, Eds., Wile, London, 1981, pp. 253-313.

[18] W. J. Orlikowski, "Using Technology and Constituting Structures: A Practice Lens for Studying Technology in Organizations", Organ. Sci., vol. 11, no. 4, Aug. 2000, pp. 404-428.
[19] L. G. Tornatzky and M. Fleischer, The processes of technological innovation. Lexington Books, Lexington, Mass, 1990

[20] R. H. Coase, "The nature of the firm", economica, vol. 4, no. 16,1937 , pp. 386-405.

[21] W. H. Delone and E. R. McLean, "The DeLone and McLean model of information systems success: a tenyear update", J. Manag. Inf. Syst., vol. 19, no. 4, 2003 , pp. 9-30.

[22] D. L. Goodhue and R. L. Thompson, "TaskTechnology Fit and Individual Performance", MIS Q., vol. 19, no. 2, Jun. 1995, pp. 213-236.

[23] T. Oliveira and M. F. Martins, "Information technology adoption models at firm level: review of literature", in European Conference on Information Management and Evaluation, 2010, p. 312-XIII.

[24] E. Karahanna, D. W. Straub, and N. L. Chervany, "Information Technology Adoption Across Time: A Cross-Sectional Comparison of Pre-Adoption and Post-Adoption Beliefs", MIS Q., vol. 23, no. 2, Jun. 1999, pp. 183-213.

[25] A. C. Boynton and R. W. Zmud, "An assessment of critical success factors", Sloan Manage. Rev., vol. 25, no. 4, 1984, pp. 17-27.

[26] J. Dregger, J. Niehaus, P. Ittermann, H. HirschKreinsen, and M. ten Hompel, "The digitization of manufacturing and its societal challenges: a framework for the future of industrial labor", IEEE ETHICS, 2016, pp. 1-3.

[27] M. Fitzgerald, N. Kruschwitz, D. Bonnet, and M. Welch, "Embracing digital technology: A new strategic imperative", MIT Sloan Manag. Rev., vol. 55, no 2,2014 , p. $1-12$.

[28] H. Hirsch-Kreinsen, "Digitization of industrial work: development paths and prospects," J. Labour Mark. Res., vol. 49, no. 1, 2016, pp. 1-14.

[29] A. Bharadwaj, O. A. El Sawy, P. A. Pavlou, and N. V. Venkatraman, "Digital business strategy: toward a next generation of insights", MIS Q., vol. 37, no. 2, 2013, pp. 471-482.

[30] G. C. Kane, D. Palmer, A. Nguyen Phillips, D. Kiron, and N. Buckley, "Strategy, not Technology, Drives Digital Transformation", MITSloan Manag. Rev., 2015.

[31] Assoc. Inf. Syst. AIS, "Senior Scholars' Basket of Journals", available at Assoc. Inf. Syst. AIS, accessed Jul. 2017

[32] L. Willcocks, E. A. Whitley, and C. Avgerou, "The ranking of top IS journals: a perspective from the London School of Economics", Eur. J. Inf. Syst., vol. 17, no. 2, Apr. 2008, pp. 163-168.

[33] R. Banker, S. Mitra, and V. Sambamurthy, "The Effects of Digital Trading Platforms on Commodity Prices in Agricultural Supply Chains", Manag. Inf. Syst. Q., vol. 35, no. 3, pp. 599-611, Sep. 2011.

[34] A. Benlian, D. Hilkert, and T. Hess, "How open is this platform? The meaning and measurement of platform 
openness from the complementors' perspective", J. Inf. Technol., vol. 30, no. 3, Sep. 2015, pp. 209-228.

[35] R. L. Nolan, "Ubiquitous IT: The case of the Boeing 787 and implications for strategic IT research", J. Strateg. Inf. Syst., vol. 21, no. 2, Jun. 2012, pp. $91-$ 102.

[36] I. D. Constantiou and J. Kallinikos, "New games, new rules: big data and the changing context of strategy", J. Inf. Technol., vol. 30, no. 1, Mar. 2015, pp. 44-57.

[37] S. Nambisan, K. Lyytinen, A. Majchrzak, and M. Song, "Digital Innovation Management: Reinventing Innovation Management Research in a Digital World”, Manag. Inf. Syst. Q., vol. 41, no. 1, Mar. 2017, pp. 223-238

[38] K. Lyytinen, Y. Yoo, and R. J. Boland Jr., "Digital product innovation within four classes of innovation networks", Inf. Syst. J., vol. 26, no. 1, Jan. 2016, pp. 47-75.

[39] W. Li, K. Liu, M. Belitski, A. Ghobadian, and N. O'Regan, "e-Leadership through strategic alignment: an empirical study of small- and medium-sized enterprises in the digital age", J. Inf. Technol., vol. 31, no. 2, Jun. 2016, pp. 185-206.

[40] F. Svahn, L. Mathiassen, and R. Lindgren, "Embracing Digital Innovation in Incumbent Firms: How Volvo Cars Managed Competing Concerns," Manag. Inf. Syst. Q., vol. 41, no. 1, Mar. 2017, pp. 239-253.

[41] M. Tarafdar, R. Singh, and P. Anekal, "Impact of ICT-enabled product and process innovations at the Bottom of the Pyramid: a market separations perspective”, J. Inf. Technol., vol. 28, no. 4, Dec. 2013, pp. 279-295.

[42] P. Almklov, T. Østerlie, and T. Haavik, "Situated with Infrastructures: Interactivity and Entanglement in Sensor Data Interpretation,” J. Assoc. Inf. Syst., vol. 15, no. 5, May 2014, pp. 263-286.

[43] I. Sila, "Do organisational and environmental factors moderate the effects of Internet-based interorganisational systems on firm performance?", Eur. J. Inf. Syst., vol. 19, no. 5, Oct. 2010, pp. 581-600.

[44] Y. B. Chang and V. Gurbaxani, "An empirical analysis of technical efficiency: The role of IT intensity and competition”, Inf. Syst. Res., vol. 24, no. 3, 2012, pp. 561-578.

[45] T. Ma and F. McGroarty, "Social Machines: how recent technological advances have aided financialisation”, J. Inf. Technol., 2017, pp. 1-17.

[46] C. Loebbecke and A. Picot, "Reflections on societal and business model transformation arising from digitization and big data analytics: A research agenda," J. Strateg. Inf. Syst., vol. 24, no. 3, 2015, pp. 149-157.

[47] O. Henfridsson and B. Bygstad, "The generative mechanisms of digital infrastructure evolution.," MIS Q., vol. 37, no. 3, Sep. 2013, pp. 907-931.

[48] J. L. Carlo, J. Gaskin, K. Lyytinen, and G. M. Rose, "Early vs. late adoption of radical information technology innovations across software development organizations: an extension of the disruptive information technology innovation model: Radical information technology innovations", Inf. Syst. J., vol. 24, no. 6, Nov. 2014, pp. 537-569.

[49] A. Quaadgras, P. Weill, and J. W. Ross, "Management commitments that maximize business impact from IT,” J. Inf. Technol., vol. 29, no. 2, 2014, pp. 114 127.

[50] S. Sarker, X. Xiao, and T. Beaulieu, "Guest editorial: qualitative studies in information systems: a critical review and some guiding principles", MIS Q., vol. 37, no. 4, 2013, pp. iii-Xviii.

[51] P. Palvia, D. Leary, E. Mao, V. Midha, P. Pinjani, and A. F. Salam, "Research methodologies in MIS: an update", Commun. Assoc. Inf. Syst., vol. 14, no. 1, 2004, pp. 526-542.

[52] R. Hirschheim, "Introduction to the Special Issue on 'Quo Vadis TAM-Issues and Reflections on Technology Acceptance Research"', J. Assoc. Inf. Syst., vol. 8 , no. 4, 2007, pp. 203-205.

[53] M. L. Markus and A. S. Lee, "Special issue on intensive research in information systems: Using qualitative, interpretive, and case methods to study information technology-third...," MIS Q., vol. 24, no. 3, 2000, pp. 473-474.

[54] K. Conboy, G. Fitzgerald, and L. Mathiassen, "Qualitative methods research in information systems: motivations, themes, and contributions", Eur. J. Inf. Syst. vol. 21, no. 2, Mar. 2012, pp. 113-118.

[55] L. Dubé and G. Paré, "Rigor in information systems positivist case research: current practices, trends, and recommendations", MIS Q., vol. 27, no. 4, 2003, pp. $597-636$.

[56] G. Walsham, "Doing interpretive research", Eur. J. Inf. Syst., vol. 15, no. 3, Jun. 2006, pp. 320-330.

[57] A. Strauss, J. Corbin, and others, Basics of qualitative research, vol. 15, Sage, Newbury Park, CA, 1990.

[58] J. Corbin and A. Strauss, "Grounded theory research Procedures, canons and evaluative criteria", Z. Für Soziol., vol. 19, no. 6, 1990, pp. 418-427.

[59] J. M. Morse, "Sampling in grounded theory", in The SAGE handbook of grounded theory, A. Bryant and K. Charmaz, Eds., Sage, Thousand Oaks, CA, 2010, pp. 229-244.

[60] A. Keller, "How to Gauge the Relevance of Codes in Qualitative Data Analysis?-A Technique Based on Information Retrieval", in Proceedings of the 13th International Conference on Wirtschaftsinformatik, 2017, pp. 1096-1110.

[61] T. H. Davenport, Process innovation: reengineering work through information technology, Harvard Business Press, 1993

[62] M. E. Porter, Competitive advantage : creating and sustaining superior performance, Free Press, New York, NY, 1985

[63] C. Bekara, "Security Issues and Challenges for the IoT-based Smart Grid", Procedia Comput. Sci., vol. 34, pp. 532-537, 2014. 